\title{
Brain and Testis Accumulation of Regorafenib is Restricted by Breast Cancer Resistance Protein (BCRP/ABCG2) and P-glycoprotein (P-GP/ABCBI)
}

\author{
Anita Kort • Selvi Durmus • Rolf W. Sparidans • Els Wagenaar • Jos H. Beijnen • Alfred H. Schinkel
}

Received: 26 September 2014 / Accepted: 12 December 2014 / Published online: 8 January 2015

(C) Springer Science+Business Media New York 2015

\begin{abstract}
Purpose Regorafenib is a novel multikinase inhibitor, currently approved for the treatment of metastasized colorectal cancer and advanced gastrointestinal stromal tumors. We investigated whether regorafenib is a substrate for the multidrug efflux transporters $A B C G 2$ and $A B C B I$ and whether oral availability, brain and testis accumulation of regorafenib and its active metabolites are influenced by these transporters.

Methods We used in vitro transport assays to assess human (h)ABCBI - or hABCG2- or murine (m)Abcg2-mediated active transport at high and low concentrations of regorafenib. To study the single and combined roles of Abcg2 and Abcbla/lb in oral regorafenib disposition and the impact of Cyp3a-mediated metabolism, we used appropriate knockout mouse strains.

Results Regorafenib was transported well by mAbcg2 and hABCG 2 and modestly by $h A B C B I$ in vitro. Abcg2 and to a lesser extent $\mathrm{Abcb} / \mathrm{a} / \mathrm{I} \mathrm{b}$ limited brain and testis accumulation of regorafenib and metabolite M2 (brain only) in mice. Regorafenib oral
\end{abstract}

Electronic supplementary material The online version of this article (doi: | 0. I007/s | | 095-0 | 4- |609-7) contains supplementary material, which is available to authorized users.

A. Kort $\cdot$ S. Durmus $\cdot$ E. Wagenaar $\cdot$ A. H. Schinkel $(\triangle)$ Division of Molecular Oncology, The Netherlands Cancer Institute, Plesmanlaan 121, 1066 CX Amsterdam, The Netherlands e-mail: a.schinkel@nki.nl

R. W. Sparidans $\cdot$ J. H. Beijnen

Division of Pharmacoepidemiology \& Clinical Pharmacology

Department of Pharmaceutical Sciences, Faculty of Science, Utrecht

University, Universiteitsweg 99, 3584 CG Utrecht, The Netherlands

\section{A. Kort $\cdot J$. H. Beijnen}

Department of Pharmacy \& Pharmacology, The Netherlands Cancer Institute/ Slotervaart Hospital, Plesmanlaan 121, I066 CX Amsterdam, The Netherlands

J. H. Beijnen

Department of Clinical Pharmacology, The Netherlands Cancer Institute, Plesmanlaan 121, 1066 CX Amsterdam, The Netherlands availability was not increased in $\mathrm{Abcg} 2^{--} ; A b c b / a / I b^{-1-}$ mice. Up till $2 \mathrm{~h}$, metabolite $\mathrm{M} 5$ was undetectable in plasma and organs.

Conclusions Brain and testis accumulation of regorafenib and brain accumulation of metabolite $M 2$ are restricted by Abcg2 and $\mathrm{Abcb} / \mathrm{a} / \mathrm{lb}$. Inhibition of these transporters may be of clinical relevance for patients with brain (micro)metastases positioned behind an intact blood-brain barrier.

KEY WORDS $A B C B \mid \cdot A B C G 2$ · brain accumulation .

regorafenib $\cdot$ testis accumulation

$\begin{array}{ll}\text { ABBREVIATIONS } \\ \text { ABC } & \text { ATP-binding cassette } \\ \text { AUC } & \text { Area under the plasma concentration-time curve } \\ \text { BBB } & \text { Blood-brain barrier } \\ \text { BCRP } & \text { Breast cancer resistance protein } \\ \text { BTB } & \text { Blood-testis barrier } \\ \text { Cmax }_{\text {max }} & \text { Maximum drug concentration in plasma } \\ \text { CNS } & \text { Central nervous system } \\ \text { GIST } & \text { Gastrointestinal stromal tumors } \\ \text { LLOQ } & \text { Lower limit of quantitation } \\ \text { LOD } & \text { Lower limit of detection } \\ \text { P-gP } & \text { P-glycoprotein } \\ \text { SD } & \text { Standard deviation } \\ \text { TKI } & \text { Tyrosine kinase inhibitor } \\ T_{\max } & \text { Time after administration of a drug to reach maximum } \\ & \text { plasma concentration }\end{array}$

\section{INTRODUCTION}

Multidrug efflux transporters of the ATP-binding cassette (ABC) protein family can have important roles in drug disposition. This impact is especially relevant for anti-cancer drugs as these drugs are usually administered close to their maximum tolerated dose. ABCB1 (P-glycoprotein) and ABCG2 
(BCRP) are expressed on the apical membrane of epithelia in a number of organs which are pivotal for absorption and elimination of drugs like liver, small intestine and kidney, but also on luminal membranes of barriers protecting sanctuary tissues like the blood-placenta, blood-testis and blood-brain barrier. At these sanctuary sites ABCB1 or ABCG2 substrates are immediately pumped out of the epithelial or endothelial cells back into the blood. As a consequence, only small amounts of drug can accumulate in, for instance, the brain to treat (micro)metastases that are present behind a functionally intact blood-brain barrier. Many anticancer drugs including tyrosine kinase inhibitors (TKIs) have been shown to be substrates of ABCG2 or ABCB1 or both by different research groups, resulting sometimes in a decreased oral availability and often in a decreased brain accumulation (1-3).

Regorafenib (BAY 73-4506, Stivarga, Supplementary Materials) is an orally dosed tyrosine kinase inhibitor targeting angiogenic, stromal and oncogenic receptor kinases, and currently being investigated for the treatment of multiple tumor types (4). In a phase III study in patients with metastasized colorectal carcinoma, regorafenib improved overall survival 6 months compared to placebo (5). This led to the approval of regorafenib by EMA and FDA in 2012. The indication for regorafenib use was recently expanded to advanced gastrointestinal stromal tumors (GIST), following a randomized double-blind placebo-controlled study of Demetri et al. $(6,7)$. Progression-free survival and disease control rate were significantly improved by regorafenib in patients with advanced GIST whose tumors had developed resistance to imatinib and sunitinib (8).

Regorafenib (fluorosorafenib) was developed as a more potent RAF-kinase inhibitor than sorafenib. These compounds have overlapping biochemical activities, however, regorafenib does not only have affinity for a broader range of antiangiogenic kinases (VEGFR1-VEGFR3) compared to sorafenib, it also targets TIE2 (tyrosine kinase with immunoglobulin and epidermal growth factor homology domain 2). The inhibition of both classes of kinases has been shown to act synergistically, resulting in a reduced tumor growth in preclinical models $(9,10)$.

Furthermore, Bruix et al. found evidence for regorafenib antitumor activity in hepatocellular carcinoma patients that had previously been treated with sorafenib (11). Regorafenib was able to delay disease progression in 25 out of 31 patients and one patient exhibited a partial response. A phase III study is currently recruiting to further investigate this effect (ClinicalTrialsGov identifier NCT01774344).

Sorafenib has been reported by various groups to be a good substrate of ABCG2 and a moderate substrate of $\mathrm{ABCB} 1$ in vitro as well as in vivo (12-15). Considering the similarity in chemical structure of regorafenib and sorafenib (Supplementary Materials, respectively) where regorafenib has an additional fluorine atom attached to the central aromatic
Fig. I In vitro transport of $5 \mu \mathrm{M}$ regorafenib. Transepithelial transport of regorafenib $(5 \mu \mathrm{M})$ was assessed in MDCK-II cells either nontransduced $(\mathbf{a}, \mathbf{b})$ or transduced with hABCBI (c, d), mAbcg2 (e, f) or hABCG2 (g, h) cDNA. At $t=0 \mathrm{~h}$, regorafenib was applied to the donor compartment and concentrations in the acceptor compartment were measured at $t=2,4$ and $8 \mathrm{~h}$ and plotted as total amount of transport (ng) in the graphs. (b, d-h) zosuquidar (5 $\mu \mathrm{M})$ and/or Kol $43(5 \mu \mathrm{M})$ were applied as indicated to inhibit hABCB I or hABCG2 and $\mathrm{mAbcg} 2$, respectively, $r$ relative transport ratio. BA ( $\square$, dashed line), translocation from basolateral to apical compartment; $A B$ ( $\bullet$ continuous line), translocation from apical to basolateral compartment. *, $P<0.05$; **** $P<0.00$ I indicates significant transepithelial transport at $t=$ $8 \mathrm{~h}$. Points, mean ( $n=3)$; bars, SD. At $t=8 \mathrm{~h}, 1 \mathrm{nmol}$ transport corresponds to an apparent permeability coefficient (Papp) of $6.2 \times 10^{-6} \mathrm{~cm} / \mathrm{s}$.

ring, regorafenib might also be a good substrate of ABCG2 and possibly ABCB1. Surprisingly, however, regorafenib is not transported by ABCG2 or ABCB1 according to the manufacturer, as tested in vitro using transduced LLC-MDR1 and wildtype LLC-PK1 cells, at clinically relevant concentrations ranging from 0.2 to $10 \mu \mathrm{M}(6)$. Regorafenib was, however, found to be an inhibitor of transport of digoxin (an ABCB1 substrate) and dipyramidole (an ABCG2 substrate) in vitro according to the same report. For this reason, a clinical phase I study (ClinicalTrialsGov identifier NCT02106845) is planned to investigate the interaction of regorafenib with digoxin and with rosuvastatin (another ABCG2 substrate).

CYP3A4 and UGT1A9 enzymes are responsible for the metabolism of regorafenib, resulting in two major and six minor metabolites. The formation of the two major circulating metabolites referred to as M2 (pyridine- $\mathcal{N}$-oxide) and M5 (pyridine- $\mathcal{N}$-oxide amide), is mediated by CYP3A4 (6). Compared to regorafenib, M2 and M5 have equal pharmacodynamic activity in vitro and they accumulate to similar plasma levels as regorafenib in patients once plasma steady state is reached $(16,17)$. This accumulation is non-linear and is attributed to enterohepatic cycling and the long elimination half-life of these metabolites (6). As a consequence, the metabolites may have a significant impact on the therapeutic efficacy of regorafenib. Interestingly, even though regorafenib was not found to be transported by $\mathrm{ABCB} 1$ or $\mathrm{ABCG} 2$ in vitro, both M2 and M5 were found to be weakly transported substrates of ABCB1 and M5 was weakly transported by ABCG2 (7). In this study, we investigated the interaction of regorafenib and its major metabolites M2 and M5 with ABCB1, ABCG2 and CYP3A4 in in vitro and in vivo in knockout mouse models.

\section{MATERIAL AND METHODS}

\section{Chemicals}

Regorafenib and zosuquidar were purchased from Sequoia Research Products (Pangbourne, UK). Zosuquidar (Eli Lilly; Indianapolis, USA) was a kind gift from Dr. O. van Tellingen 
a

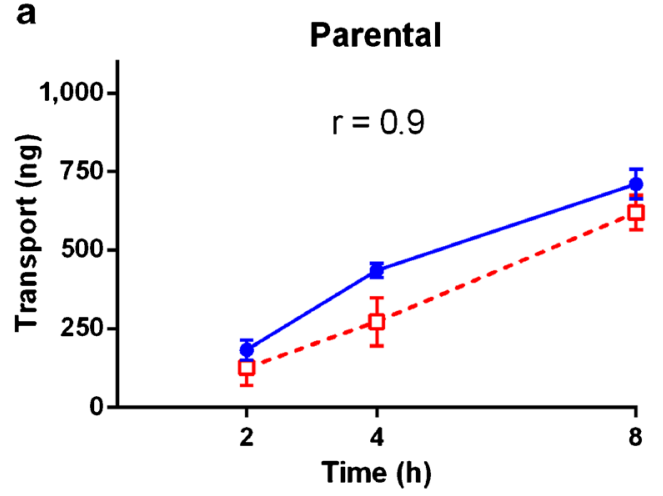

C

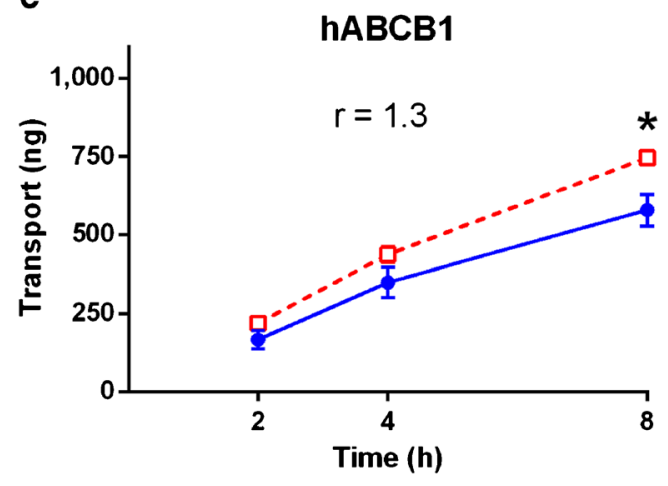

e

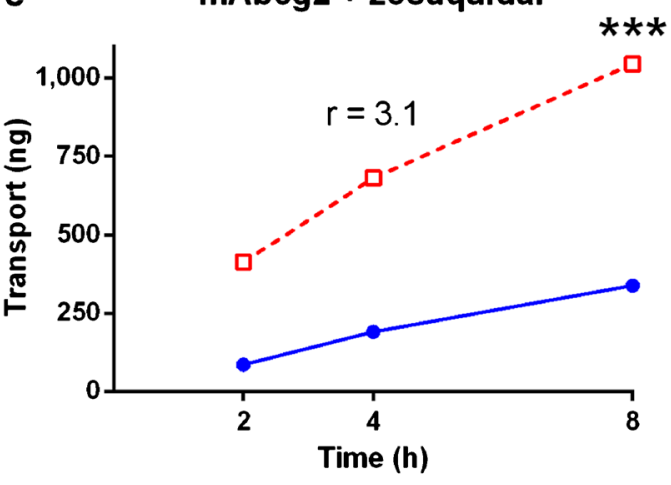

g

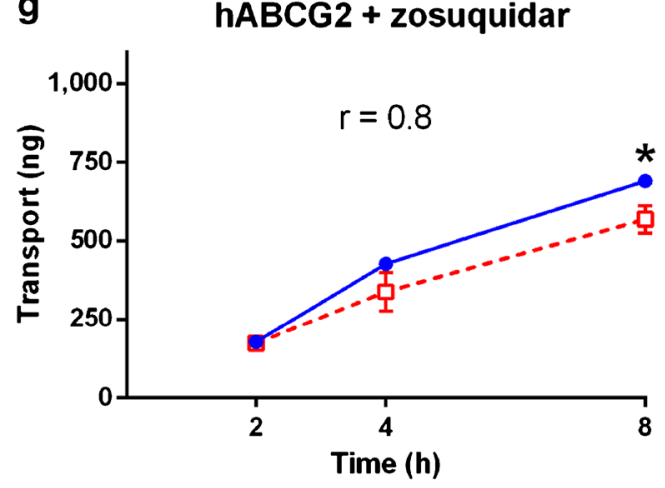

b

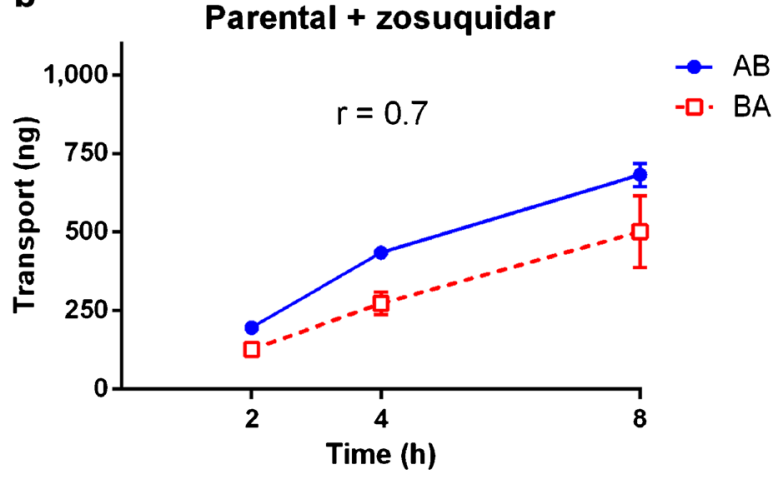

d

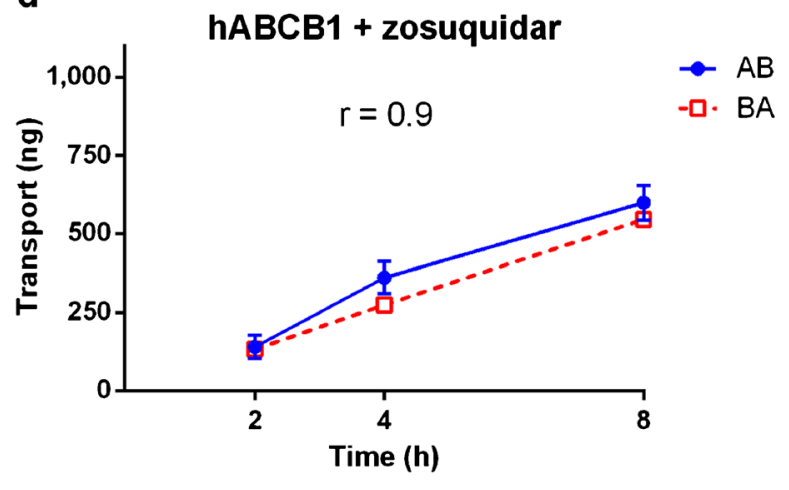

f $\quad$ mAbcg2 + zosuquidar + Ko143

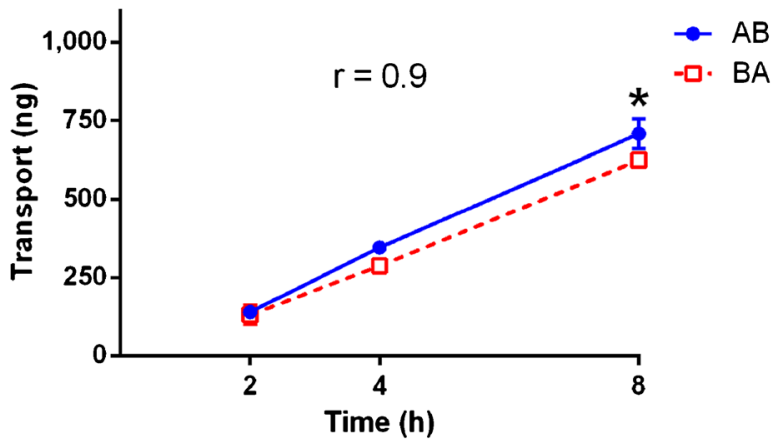

h hABCG2 + zosuquidar + Ko143

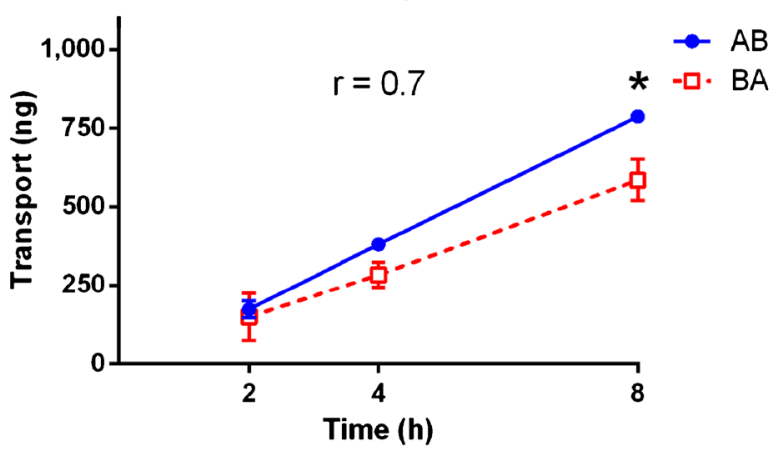

(The Netherlands Cancer Institute, Amsterdam, The Netherlands) and Kol43 was obtained from Tocris Bioscience (Bristol, UK). Methoxyflurane (Metofane ${ }^{\circledR}$ ) was obtained from Medical
Developments Australia (Melbourne, Australia). Heparin (5000 IU ml ${ }^{-1}$ ) was obtained from Leo Pharma (Breda, The Netherlands). Bovine Serum Albumin (BSA) Fraction V, 
was purchased from Roche (Mannheim, Germany). Chemicals used for the bioanalytical assay of regorafenib were described previously (18); metabolites M2 and M5 were supplied by ALSACHIM (Illkirch Graffenstaden, France). All other chemicals and reagents were obtained from Sigma-Aldrich (Steinheim, Germany).

\section{Transport Assays}

Polarized Madin-Darby Canine Kidney (MDCK-II) cell lines transduced with human (h)ABCB1, murine (m)Abcg2 and hABCG2 cDNA were used and cultured as described previously (19). Transepithelial transport assays were performed in triplicate on 12-well microporous polycarbonate membrane filters (3.0- $\mu \mathrm{m}$ pore size, Transwell 3402, Corning Inc., Lowell, MA) as described previously (20). In short, cells were allowed to grow an intact monolayer in 3 days. On day 3, cells were pre-incubated with the relevant inhibitors for $1 \mathrm{~h}$. To inhibit endogenous canine Abcb1 in the MDCK-II Abcg2 and MDCK-II ABCG2 cell lines, we added $5 \mu \mathrm{M}$ zosuquidar (ABCB1 inhibitor) to the culture medium during the entire experiment. The experiment was started by replacing the incubation medium from the donor compartment with freshly prepared drug-containing medium. At 2, 4, 8 and 24 h, $50 \mu \mathrm{l}$ samples were collected from the acceptor compartment and stored at $-30^{\circ} \mathrm{C}$ until analysis. The amount of transported drug was calculated after correction for volume loss due to sampling at each time point. Active transport was expressed by the transport ratio $(r)$, which is defined as the amount of apically directed transport divided by the amount of basolaterally directed transport at a defined time point.

\section{Animals}

Male wild-type, $A b c b 1 a / 1 b^{-/-}$(21), $A b c g 2^{-/-}$(22), $A b c g 2^{-/-} ; A b c b 1 a /$ $1 b^{-/-}$(23) and Cyp3a $a^{-/-}$mice (24), all of a $>99 \%$ FVB genetic background were used. Mice between 9 and 13 weeks of age were used in groups of five mice per strain. The mice were kept in a temperature-controlled environment with a 12-h light/ dark cycle and received a standard diet (AM-II, Hope Farms, Woerden, The Netherlands) and acidified water ad libitum. Animals were housed and handled according to institutional guidelines in compliance with Dutch legislation.

\section{Drug Solutions}

Regorafenib was dissolved in DMSO at $20 \mathrm{mg} / \mathrm{ml}$ and diluted 20-fold with a vehicle mixture containing $10 \%(\mathrm{v} / \mathrm{v})$ polysorbate $80,6.5 \%(\mathrm{v} / \mathrm{v})$ ethanol and $2.5 \%(\mathrm{w} / \mathrm{v})$ glucose in water, to obtain a $1 \mathrm{mg} / \mathrm{ml}$ solution. Regorafenib was administered orally at a dose of $10 \mathrm{mg} / \mathrm{kg}(10 \mu \mathrm{l} / \mathrm{g})$. All working solutions were prepared freshly on the day of experiment.

\section{Plasma and Tissue Pharmacokinetics of Regorafenib}

To minimize variation in absorption, mice were fasted for $2 \mathrm{~h}$ prior to oral administration of regorafenib using a bluntended needle. For the pharmacokinetic experiment, $50 \mu \mathrm{l}$ blood samples were drawn from the tail vein using heparincoated capillaries (Sarstedt, Germany) at 0.5, 1, 2, 4 and $8 \mathrm{~h}$. At $24 \mathrm{~h}$ mice were anesthetized using isoflurane and blood was collected via cardiac puncture. Immediately thereafter, mice where sacrificed by cervical dislocation and a set of organs was rapidly removed, weighed and subsequently frozen as whole organ at $-30^{\circ} \mathrm{C}$. Prior to analysis, organs were allowed to thaw and homogenized in appropriate volumes of $1 \%(\mathrm{w} / \mathrm{v})$ BSA in water using a FastPrep $\mathbb{R}-24$ device (MP Biomedicals, SA, California, USA). Blood samples were immediately centrifuged after collection at $2100 \mathrm{~g}$ for $6 \mathrm{~min}$ at $4^{\circ} \mathrm{C}$, and plasma was collected and stored at $-30^{\circ} \mathrm{C}$ until analysis.

\section{Relative Accumulation of Regorafenib in Brain, Testis, Liver and Kidney}

Mice were fasted for $2 \mathrm{~h}$ before oral gavage of regorafenib. At $0.25,0.5$ and $1 \mathrm{~h}$ blood was collected by tail vein sampling. At $2 \mathrm{~h}$, roughly corresponding with the $\mathrm{T}_{\max }$, mice were anesthetized with isoflurane and blood was collected by cardiac puncture. Immediately thereafter mice were sacrificed and brain, testis, liver and kidney were removed and processed as described above. Regorafenib concentration in brain tissue was corrected for the presence of plasma in the vascular space $(1.4 \%)(25)$.

\section{Drug Analysis}

Regorafenib concentration in culture medium was analyzed with a previously reported liquid-chromatography tandem mass spectrometric (LC-MS/MS) assay for regorafenib, with a calibration curve ranging from 25 to $25,000 \mathrm{ng} / \mathrm{ml}(18)$. Plasma and tissue homogenates were analyzed with an extended LC-MS/MS assay using a gradient elution, where two active metabolites were included in the previously mentioned regorafenib assay at a higher sensitivity. The calibration ranges covered $10-10,000 \mathrm{ng} / \mathrm{ml}$ with an extrapolated lower limit of detection of $5 \mathrm{ng} / \mathrm{ml}$ for both regorafenib and its metabolites (unpublished data). Tissue concentrations were accordingly corrected for their individual weights, resulting in $n g$ regorafenib per gram tissue.

\section{Statistics and Pharmacokinetic Calculations}

The unpaired two-tailed Student's $t$-test was used to determine significant transepithelial transport for heteroscedastic data. The area under the curve (AUC) of the plasma concentration-time curve was calculated using the trapezoidal 
rule, without extrapolating to infinity. The peak plasma concentration $\left(\mathrm{C}_{\max }\right)$ and the time to reach peak plasma concentration $\left(\mathrm{T}_{\max }\right)$ were determined from individual concentration-time data. Ordinary one-way analysis of variance (ANOVA) was used to determine significant differences between groups. Post-hoc Tukey's multiple comparison test was used to compare significant differences between individual groups. When variances were not homogeneously distributed, data were log-transformed before applying statistical tests. Differences were considered statistically significant when $P<0.05$. Data are presented as mean $\pm \mathrm{SD}$ with each experimental group containing five mice.

\section{RESULTS}

\section{Regorafenib is Modestly Transported by hABCB I and Efficiently by $\mathrm{mAbcg} 2$ and $\mathrm{hABCG} 2$ In Vitro}

Polarized MDCK-II cell lines transduced with hABCB1, mAbcg2 or hABCG2 were used to assess active transport of $5 \mu \mathrm{M}$ regorafenib. We observed a slight amount of basolaterally directed transport in the parental cells, presumably by endogenous as yet unidentified transporters (Fig. la, b). Bearing this in mind, there was a modest apically directed transport of regorafenib by hABCB1 $(r=1.3)$ counteracting the basolaterally directed transport seen in the parental line as shown in Fig. 1c. This transport was inhibited by zosuquidar (Fig. 1d, $r=0.9$ ). Apically directed transport of regorafenib was highest in mAbcg2-expressing cells $(r=3.1)$ and this transport was efficiently inhibited by Kol43 (Fig. 1e, f, $r=0.9$ ). In contrast to mAbcg2, hABCG2 appeared to have no effect on the transport of regorafenib (Fig. $1 \mathrm{~g}, r=0.8$ ). As $5 \mu \mathrm{M}$ regorafenib might saturate a possible modest transport activity of hABCG2, we lowered the concentration in the assay to $1 \mu \mathrm{M}$. Results similar to the previous experiment were obtained for the parental, hABCB1 and mAbcg2 expressing cells, although the background basolaterally directed transport of regorafenib in the parental cells was even more pronounced, and partly also inhibited by zosuquidar (Fig. 2a-f). However, now hABCG2 showed a clear apically directed transport of regorafenib (Fig 2g, $r=2.7$ ) which could be completely inhibited by Kol43 (Fig. 2h, $r=1.0$ ). These data suggest that hABCG2-mediated transport of regorafenib gets effectively saturated between 1 and $5 \mu \mathrm{M}$ in this test system.

\section{No Substantial Effect of mAbcb I or mAbcg2 on Plasma Pharmacokinetics of Oral Regorafenib in Mice}

As regorafenib is orally administered to patients, the mice received regorafenib by oral gavage into the stomach at a dose of $10 \mathrm{mg} / \mathrm{kg}$. The time to reach peak plasma concentrations was about $2 \mathrm{~h}$ in each strain (Fig. 3). The experimental variation was quite high, and although the AUCs in the single knockout strains were significantly reduced compared to WT, to 0.8-fold in $A b c g 2^{-/-}$mice $(P<0.01)$ and to 0.5 -fold in $A b c b 1 a / 1 b^{-/-}(P<0.001)$, the combination $A b c g 2^{-/-} ; A b c b 1 a / 1 b^{-/-}$ mice had an AUG close to that of the WT mice. Collectively, this indicates that there is no substantial effect of these transporters on restricting the oral availability of regorafenib. This was further supported by plasma curves obtained in a subsequent short-term $(2 \mathrm{~h})$ oral regorafenib experiment in these mouse strains (see below).

\section{Abcg2 and Abcbla/lb Limit Regorafenib Brain and Testis Accumulation in Mice}

Although regorafenib was largely eliminated from the plasma within $24 \mathrm{~h}$, brain concentrations were increased by 4.4 -fold in $A b c g 2^{-/-}$mice and by 5.5 -fold in $A b c g 2^{-/-} ; A b c b 1 a / 1 b^{-/-}$mice compared to WT mice (Fig. 4a). Also after correction for the individual plasma concentrations and AUCs, comparable effects were seen for $A b c g 2^{-/-}$and $A b c g 2^{-/-} ; A b c b 1 a / 1 b^{-/-}$mice, whereas there was no effect of single Abcbla/1b deficiency on brain-to-plasma ratio or brain accumulation compared to WT mice, as shown in Fig. $4 \mathrm{~b}$ and c.

The impact of transporter proteins is especially relevant around the maximum plasma concentration. Mice were therefore sacrificed $2 \mathrm{~h}$ after oral administration of $10 \mathrm{mg} / \mathrm{kg}$ regorafenib. Plasma concentration curves up to $2 \mathrm{~h}$ were similar for all mouse strains (Fig. 5a), further confirming that the absence of Abcg2 and/or Abcbla/lb did not have a strong effect on the plasma AUC. As shown in Table I and Fig. 6a, Abcg2 deficiency resulted in a 3.7-fold increase in regorafenib brain concentration compared to WT mice. Single Abcbla/lb knockout had a small but not significant effect on brain concentration, but when both Abcg2 and Abcbla/ lb were absent the brain concentration further increased to a 7.9-fold higher brain concentration compared to WT mice. This was a significant 2.1-fold increase compared to the effect of Abcg2 deficiency alone $(P<0.001)$. Brain accumulation values (Fig. 6b) yielded essentially the same results. The data indicate that Abcg2 has a clear effect on restricting brain accumulation of regorafenib, and Abcbl a modest effect that only becomes clearly apparent in the absence of Abcg2.

The blood-testis barrier (BTB) resembles the blood-brain barrier $(\mathrm{BBB})$ with regard to the presence of $\mathrm{Abcg} 2$ and Abcbla/1b in the endothelial cells of blood capillaries. Therefore testis was also analyzed to assess whether regorafenib accumulation was affected by Abcg2, Abcbla/1b or both. As shown in Fig. 6c and d, absence of Abcg2 resulted in a 2.9-fold increase in regorafenib accumulation and additional knockout of Abcbla/lb further increased regorafenib accumulation by about 1.5 -fold. In contrast to the brain data, single knockout of Abcbla/1b already resulted in a 
significant, 2-fold increase of regorafenib accumulation in testis compared to that in wild type mice $(P<0.01)$. These results show that both Abcg2 and Abcbla/lb, alone or in combination, contribute to restricting testis accumulation of regorafenib, with Abcg2 being the predominant transporter protein. Regorafenib concentrations in well-perfused organs like liver and kidney did not differ significantly between the strains (Supplementary Materials), indicating that Abcg2 and Abcbla/lb did not have a strong impact on the regorafenib disposition to these organs. Consequently, the relative brain accumulation of regorafenib in WT mice was about $2 \%$ of the liver accumulation, whereas brain or testis accumulation of regorafenib in the absence of Abcg2 and Abcbla/1b were increased to $17 \%$ or $30 \%$ of the liver accumulation, respectively (compare Fig. $6 \mathrm{~b}$ and $\mathrm{d}$ with Supplementary Materials).

\section{Active Regorafenib Metabolite M2 is Able to Penetrate the Brain in Abcg2 ${ }^{-/-} ; A b c b / a / I^{-/-}$Mice}

To investigate the effect of CYP3A enzymes on regorafenib metabolite formation, we administered $10 \mathrm{mg} / \mathrm{kg}$ regorafenib orally to $\operatorname{Cyp} 3 a^{-/-}$mice. As shown in Fig. 5b, M2 was already detectable after $15 \mathrm{~min}$, with a likely $\mathrm{C}_{\max }$ at roughly $1-2 \mathrm{~h}$ in WT mice. No detectable amount of M2 was found in plasma of Cyp3 $a^{-/-}$mice up to $2 \mathrm{~h}$, whereas similar M2 AUCs were obtained for WT, $A b c g 2^{-/-}, A b c b 1 a / 1 b^{-/-}$and $A b c g 2^{-/-} ; A b c b 1 a / 1 b^{-/-}$mice corresponding with roughly $2 \%$ of the regorafenib $\mathrm{AUC}_{0-2}$. M2 brain concentrations were below the lower limit of quantitation (LLOQ) in all mouse strains and even below the limit of detection (LOD; $<5 \mathrm{ng} / \mathrm{ml}$ ), with the exception of $A b c g 2^{-/-} ; A b c b 1 a / 1 b^{-/-}$ mice. There was therefore a minimally 2.3 -fold increase in brain concentration of M2 in $A b c g 2^{-/-} ; A b c b 1 a / 1 b^{-/-}$mice after $2 \mathrm{~h}$ compared to all the other tested mouse strains (Table I, Supplementary Materials). The amount of metabolite formed within $2 \mathrm{~h}$ after regorafenib administration was too low to observe BTB passage of M2, although small amounts of M2 were detectable. In liver and kidney tissue of all strains except for the Cyp3a knockout mice (not shown). The other active metabolite, M5, was not detected within $2 \mathrm{~h}$ in plasma or in the analyzed tissues. Together, the data show that formation of M2 is strongly dependent on Cyp3a activity in the mouse, and that M2 brain accumulation is restricted by Abcg2 and/or Abcbla/1b.

\section{DISCUSSION}

We found that regorafenib is transported by mAbcg2 and modestly by hABCG2 and hABCB1. This is evidenced in vitro
Fig. 2 In vitro transport of I $\mu M$ regorafenib. Transepithelial transport of regorafenib (I $\mu \mathrm{M})$ was assessed in MDCK-II cells either nontransduced $(\mathrm{a}, \mathbf{b})$ or transduced with hABCBI (c, d), mAbcg2 (e, f) or hABCG2 (g, h) cDNA. At $t=0 \mathrm{~h}$, regorafenib was applied to the donor compartment and concentrations in the acceptor compartment were measured at $t=2,4$ and $8 \mathrm{~h}$ and plotted as total amount of transport (ng) in the graphs $(n=3) .(\mathbf{b}, \mathbf{d}-\mathbf{h})$ Zos. (zosuquidar, $5 \mu \mathrm{M}$ ) and/or Kol $43(5 \mu \mathrm{M})$ were applied as indicated to inhibit $h A B C B \mid$ or $h A B C G 2$ and $m A b c g 2$, respectively. $r$ relative transport ratio. $B A(\square$, dashed line), translocation from basolateral to apical compartment; $A B(\bullet$, continuous line), translocation from apical to basolateral compartment. *, $P<0.05$; ***, $P<0.00$ I indicates significant transepithelial transport at $t=8 \mathrm{~h}$. Points, mean $(n=3)$; bars, SD. At $t=8 \mathrm{~h}$, I nmol transport corresponds to an apparent permeability coefficient (Papp) of $3.1 \times 10^{-5} \mathrm{~cm} / \mathrm{s}$.

by positive transport ratios and full inhibition of the apical transport by specific inhibitors. Using various knockout mouse strains, we were able to extend these findings in vivo. We showed that even though regorafenib oral availability was not affected by Abcg2 or Abcbla/1b, the brain and testis accumulation were clearly restricted by Abcg2 and Abcbla/ 1b. Lastly, we show that the active metabolite M2 is primarily formed by Cyp3a enzymes and was able to better penetrate the brain in the absence of both Abcg2 and Abcbla/lb, just like regorafenib.

Maximal plasma concentrations around $3.5 \mu \mathrm{M}$ are reached in man after a single regorafenib dose. After continuous daily dosing, regorafenib accumulates to steady state concentrations in the range of 5 to $7 \mu \mathrm{M}$ (16). These concentrations are in the same order of magnitude with the concentrations we found in plasma of mice (up to $12 \mu \mathrm{M}$ ) after $10 \mathrm{mg} / \mathrm{kg}$ oral dosing in vivo. From this perspective, we think that our in vivo findings might provide a good basis for extrapolation to the clinical situation, also as regorafenib binding to mouse and human plasma poteins is similar $(\sim 99.5 \%)(6)$.

Interestingly, our in vitro findings contrast with what the manufacturer reported earlier. They found that regorafenib was an inhibitor of hABCG2, but not a transported substrate of either hABCB1 or hABCG2 in vitro using LLC-ABCB1 and MDCK-II-ABCG2 cell lines with concentrations ranging from 0.2 to $10 \mu \mathrm{M}(6,7,26)$. Although they also performed transwell membrane experiments, there may be several reasons for the discrepancy between our and their findings such as differences in assay sensitivity, transporter expression level and cell types used in these assays. From our own experience we know that it is difficult to maintain adequate hABCG2 expression in MDCK-II cells, and studies of hABCB1 function in LLC-PK1 cells can be compromised by the significant level of endogenous porcine ABCG2 function in these cells when the test drug (like regorafenib) is also an ABCG2 substrate. Although speculative, perhaps these factors have contributed to different outcomes of our studies and those of the manufacturer. 

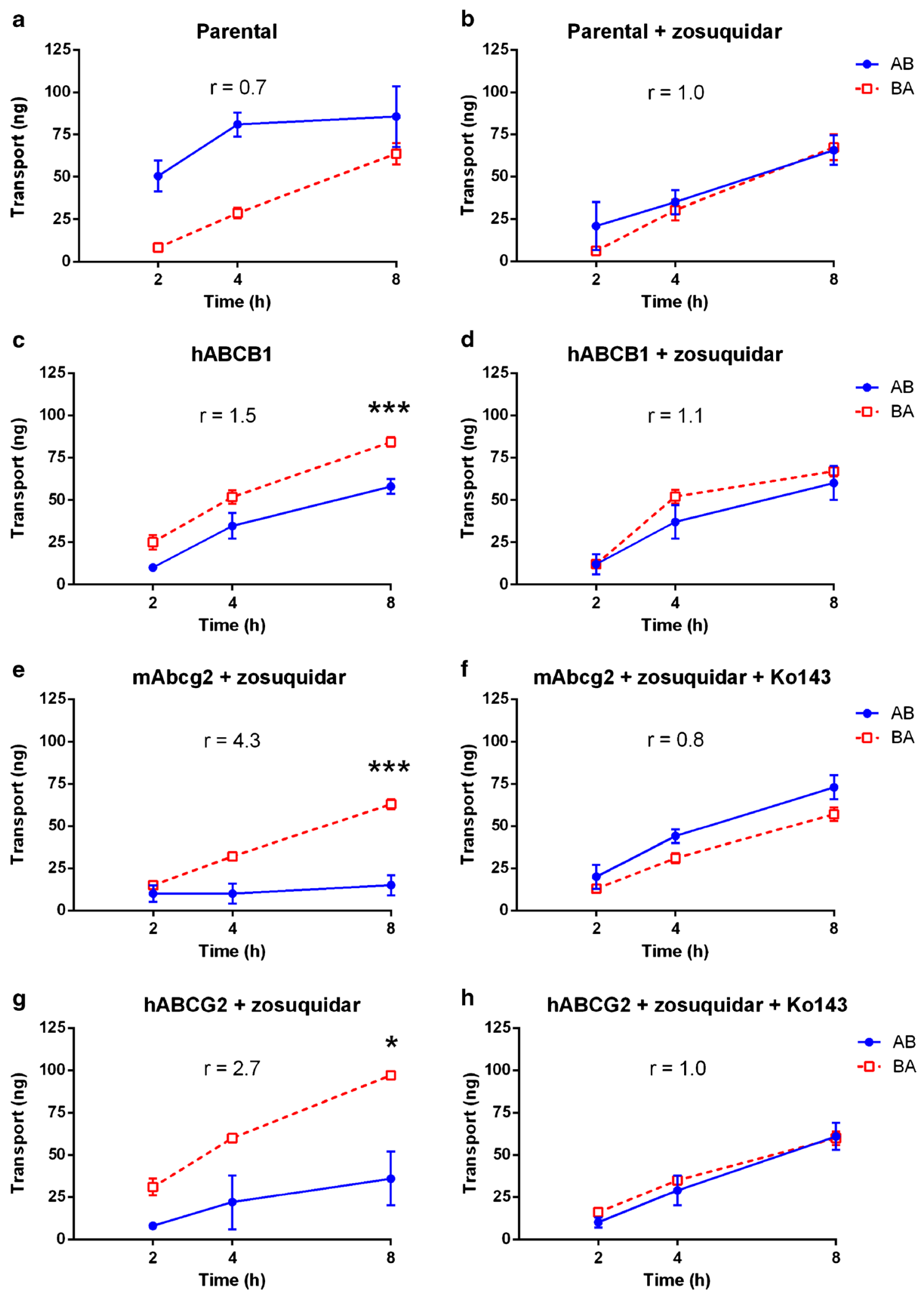

We found that $5 \mu \mathrm{M}$ regorafenib was actively transported by $\mathrm{mAbcg} 2$ in vitro, while hABCG2-mediated transport was saturated at this concentration. Lowering the concentration to
$1 \mu \mathrm{M}$ was enough to demonstrate that regorafenib was indeed a transported substrate of hABCG2. As discussed before $(14,27,28)$, a lower in vitro transport capacity of hABCG2 


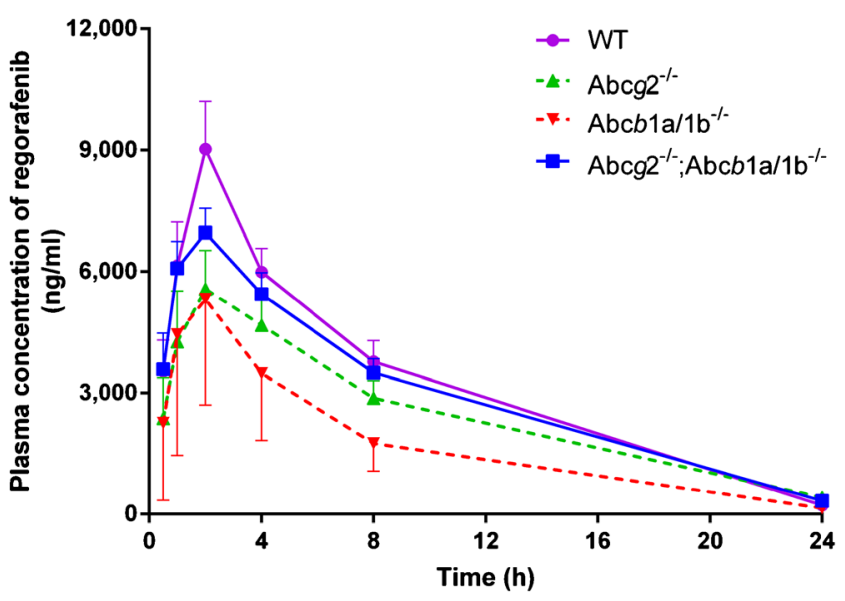

Fig. 3 Plasma concentration-time curves $\left(\mathrm{AUC}_{0-24}\right)$ of regorafenib in male

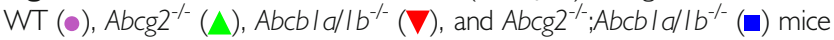
over 24 h. Points, mean $(n=5)$; bars, SD.

versus $\mathrm{mAbcg} 2$ that is consistently seen for many drugs in these cells may relate to the difficulty in obtaining MDCKII cell lines with a high hABCG2 expression and activity. Another possibility is that the $\mathrm{Km}$ of regorafenib for hABCG2 is lower than that for mAbcg2. In line with the in vitro results, we found a substantial impact of $\mathrm{mAbcg} 2$ in vivo at the $\mathrm{BBB}$ at plasma concentrations in the clinical range of up to $\sim 12 \mu \mathrm{M}$ regorafenib. In addition, Uchida et al. demonstrated that hABCG2 is 1.9-fold more expressed in human brain microvessels than mAbcg2 in the murine brain (29). Therefore the role of hABCG2 in the brain disposition of regorafenib could be even more pronounced in man than we found in the mouse.

Our findings show that regorafenib is a moderate Abcbla/lb and a good Abcg2 substrate at the BBB. Absence of Abcbla/lb did not affect the brain disposition of regorafenib at the $\mathrm{C}_{\max }(t=2 \mathrm{~h})$, while deficiency of Abcg2 led to a 3.6-fold increase in brain accumulation. However, the additional contribution of Abcbla/ $1 \mathrm{~b}$ for the brain accumulation became apparent in the absence of both transporters, leading to an 8.2-fold increase. This disproportionate effect is seen more often for TKIs and other drugs that are shared Abcg2 and Abcbl substrates and is well explained by various published theoretical pharmacokinetic models (30-32).

Regorafenib is one of the very few TKIs (including sorafenib and CYT387) whose brain disposition is dominated by Abcg2 and not by Abcbla, whereas their oral availability was not affected by the absence of these transporters $(13,14,33)$. Brain accumulation of the majority of the TKIs and other targeted anti-cancer drugs tested so far were shown to be affected mainly or only by Abcbla/lb deficiency such as axitinib (12), cediranib (34), crizotinib (35), everolimus (36), trametinib (37) and veliparib (38). One of the reasons for this is likely to be the approximately 3 to 4 -fold higher expression of Abcbla protein compared to Abcg2 at the mouse BBB $(39,40)$, further emphasizing the good substrate specificity of Abcg2 for regorafenib. Although regorafenib has high structural similarity to sorafenib, regorafenib seems to have a better oral bioavailability and a more delayed $\mathrm{T}_{\max }$ compared to sorafenib in patients, whereas several other pharmacokinetic parameters seem to be similar (Supplementary Materials) (17,41).

In this study, we observed a clear impact of contextdependency in ABC transporter activity. We found that absence of Abcbla/ lb and Abcg2 does not affect oral availability, but does influence brain and testis accumulation of regorafenib. Similar effects have been described previously for example with sorafenib, sunitinib and CYT387 (14,28,33). Additionally, we found a significant detectable impact of single Abcbla/lb knockout on the regorafenib accumulation in the testis, while there was a slight but insignificant impact of Abcbla/lb absence in the brain. This could perhaps be attributed to the relatively lower amount of mAbcg2 present in testis compared to the brain in mice (42), whereas intrinsic differences in tightness of the BTB a

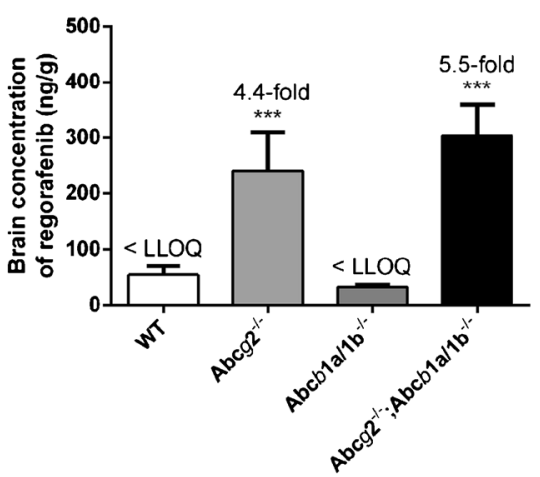

b

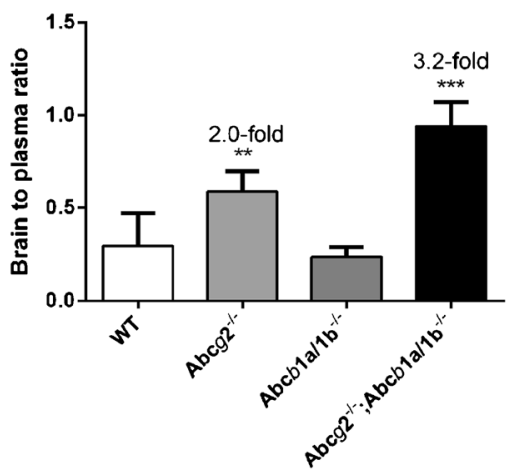

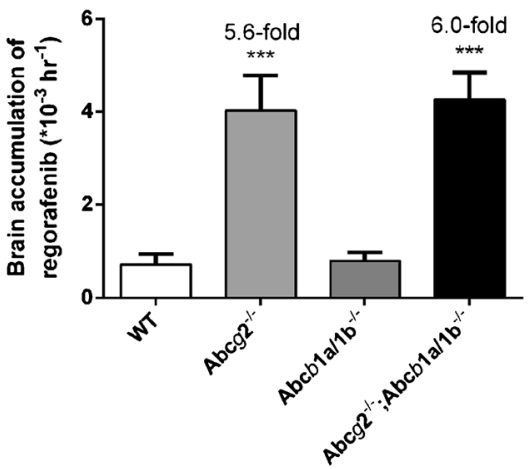

Fig. 4 Brain concentration (a), brain-to-plasma ratios (b) and relative brain accumulation (c) of regorafenib in male WT, Abcg $2^{-1-}, A b c b / a / I b^{-1-}$ and $A b c g 2^{-1}$ ; Abcb l a/ I $b^{-1-}$ mice $24 \mathrm{~h}$ after oral administration of $10 \mathrm{mg} / \mathrm{kg}$ regorafenib. ***, $P<0.0 \mathrm{I}$; ****, $P<0.00 \mathrm{I}$ compared with WT mice. Data are presented as mean \pm $\mathrm{SD}(n=5)$. Where necessary, data were log-transformed to normalize the SDs between study groups. 

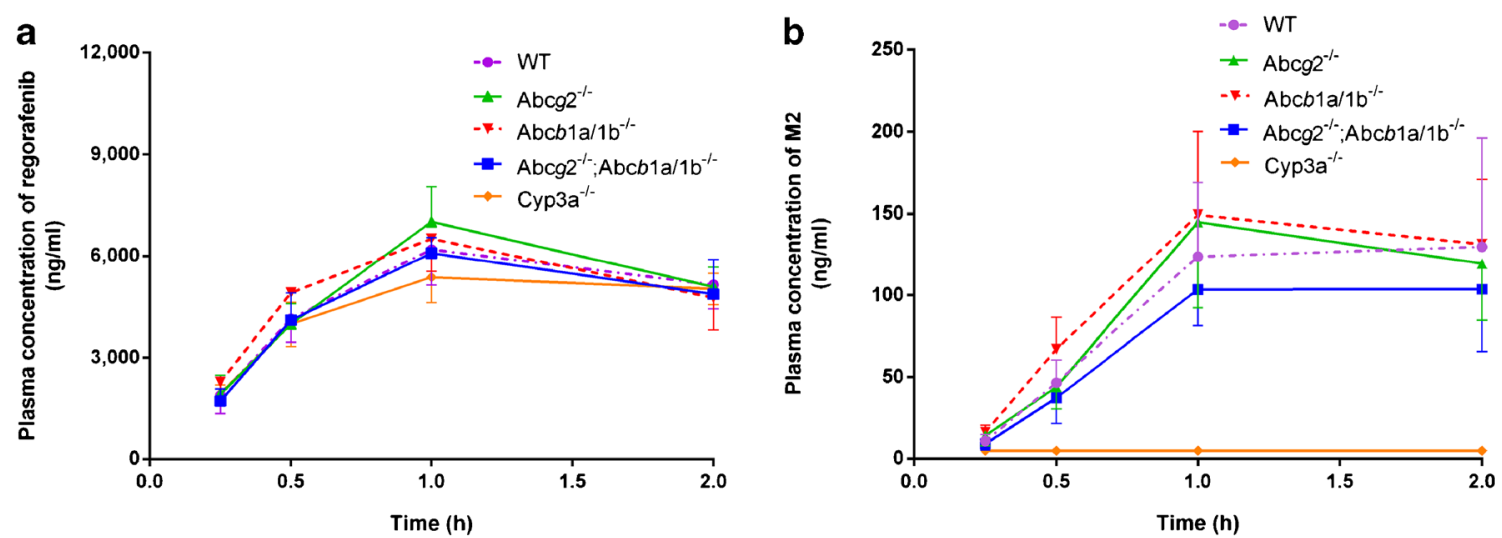

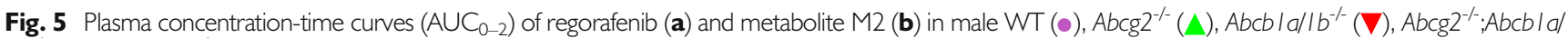
$\mathrm{Ib}^{-/-}(\mathbf{\square})$ and $\mathrm{Cyp} \mathrm{a}^{-/-}(\diamond)$ mice over $2 \mathrm{~h}$ after oral administration of $10 \mathrm{mg} / \mathrm{kg}$ regorafenib. Points, mean $(n=5)$; bars, SD.

versus $\mathrm{BBB}$ may also have played a role in their slightly different behavior (43).

Unlike M5, formation of M2 appears to be fast and solely mediated by Cyp3a enzymes in the mouse. We were able to measure M2 already $15 \mathrm{~min}$ after oral administration of regorafenib in all strains except for the Cyp3a knockout mice, whereas we could not detect M5 after $2 \mathrm{~h}$. As trace amounts of M2, only slightly above LOD, were measured in the brain of $A b c g 2^{-/}$; $A b c b 1 a / 1 b^{-1-}$ mice, it is likely that M2 is also a substrate of one or both of these transporters. We think that the single bolus administration of regorafenib was

Table I Pharmacokinetic Parameters of Regorafenib and the Metabolite M2, 2 and $24 \mathrm{~h}$ after Oral Administration of $10 \mathrm{mg} / \mathrm{kg}$ Regorafenib to Male Wild-Type,

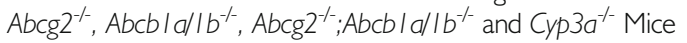

\begin{tabular}{|c|c|c|c|c|c|c|}
\hline \multirow[t]{2}{*}{ Parameter } & & \multicolumn{5}{|l|}{ Genotype } \\
\hline & & Wild-type & $A b c g 2^{-1-}$ & $A b c b / a / l b^{-1-}$ & $A b c g 2^{-1-} ; A b c b \mid a / I b^{-1-}$ & Сур $3 a^{--}$ \\
\hline Plasma $\mathrm{AUC}_{(0-24)}(\mu \mathrm{g} * \mathrm{~h} / \mathrm{ml})$ & \multirow{7}{*}{$\begin{array}{l}\text { Regorafenib } \\
24 \mathrm{~h}\end{array}$} & $77 \pm 8$ & $59 \pm 8^{* *}$ & $42 \pm 11 * * * * *$ & $7 \mid \pm 5$ & \\
\hline$C_{\max }(\mu g / m l)$ & & $9.0 \pm 1.2$ & $5.6 \pm 1.0$ & $6.5 \pm 1.7$ & $7.0 \pm 0.6$ & \\
\hline$T_{\max }(h)$ & & 2 & 2 & $1-4$ & 2 & \\
\hline$C_{\text {brain }}(n g / g)$ & & $55 \pm 15^{\#}$ & $240 \pm 69 * * * *$ & $32 \pm 5^{*,+++, \#}$ & $303 \pm 56$ ***** & \\
\hline Fold increase $\mathrm{C}_{\text {brain }}$ & & 1.0 & 4.4 & 0.6 & 5.5 & \\
\hline$P_{\text {brain }}\left(* 10^{-3} h^{-1}\right)$ & & $0.7 \pm 0.2$ & $4.0 \pm 0.8 * * * *$ & $0.8 \pm 0.2^{+++}$ & $4.3 \pm 0.6^{* * * *}$ & \\
\hline Fold increase $P_{\text {brain }}$ & & 1.0 & 5.6 & I.1 & 6.0 & \\
\hline Plasma $\mathrm{AUC}_{(0-2)}\left(\mu g^{*} \mathrm{~h} / \mathrm{ml}\right)$ & \multirow{7}{*}{$\begin{array}{l}\text { Regorafenib } \\
2 \mathrm{~h}\end{array}$} & $9.2 \pm 1.3$ & $9.8 \pm 1.2$ & $9.7 \pm 1.4$ & $9.0 \pm 1.0$ & $8.5 \pm 0.8$ \\
\hline$C_{\max }(\mu g / m l)$ & & $6.2 \pm 1.0$ & $7.0 \pm 1.0$ & $6.5 \pm 1.0$ & $6.1 \pm 0.5$ & $5.5 \pm 0.5$ \\
\hline $\mathrm{T}_{\max }(\mathrm{h})$ & & $1-2$ & 1 & I & I & $\mathrm{I}-2$ \\
\hline$C_{\text {brain }}(n g / g)$ & & $482 \pm 112$ & $1808 \pm|6|^{* * * *++}$ & $689 \pm 104^{+++}$ & $3804 \pm 585^{* * * *}$ & $522 \pm 199$ \\
\hline Fold increase $\mathrm{C}_{\text {brain }}$ & & 1.0 & 3.7 & 1.4 & 7.9 & 1.1 \\
\hline$P_{\text {brain }}\left(* 10^{-3} \mathrm{~h}^{-1}\right)$ & & $52 \pm 11$ & $188 \pm 33$ ****,++ & $72 \pm 10^{+++}$ & $428 \pm 78$ ***** & $66 \pm 26$ \\
\hline Fold increase $P_{\text {brain }}$ & & 1.0 & 3.6 & 1.4 & 8.2 & 1.3 \\
\hline Plasma $\mathrm{AUC}_{(0-2)}\left(\mathrm{ng} \mathrm{g}^{*} / \mathrm{ml}\right)$ & \multirow{5}{*}{$\begin{array}{l}M 2 \\
2 \mathrm{~h}\end{array}$} & $178 \pm 68$ & $188 \pm 62$ & $207 \pm 65$ & $146 \pm 37$ & $<9^{\#}$ \\
\hline $\mathrm{C}_{\max }(\mathrm{ng} / \mathrm{ml})$ & & $|43 \pm 6|$ & $145 \pm 53$ & $|50 \pm 5|$ & $115 \pm 27$ & $<5^{\#}$ \\
\hline $\mathrm{T}_{\max }(\mathrm{h})$ & & $1-2$ & I & $1-2$ & $\mathrm{I}-2$ & n.a. \\
\hline$C_{\text {brain }}(n g / g)$ & & $<14^{\#}$ & $<14^{\#}$ & $<13^{\#}$ & $33 \pm 14$ & $<15^{\#}$ \\
\hline$P_{\text {brain }}\left(* 10^{-3} h^{-1}\right)$ & & n.a. & n.a. & n.a. & $226 \pm 79$ & n.a. \\
\hline
\end{tabular}

AUC area under the plasma concentration-time curve, $C_{\max }$ maximum drug concentration in plasma, $T_{\max }$ the time (h) after drug administration needed to reach maximum plasma concentration, $C_{\text {brain }}$ brain concentration, $P_{\text {brain }}$ brain accumulation (brain concentration devided by AUC), n.a. not applicable

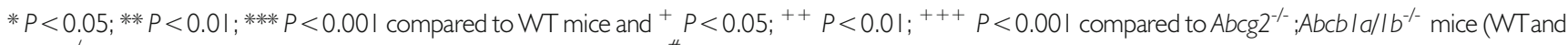
Сур $3 a^{-1-}$ ) significance data for this last comparison are not shown; ${ }^{\#}$ maximal value, calculated with the lower limit of detection in the used LC-MS/MS assay $(5 \mathrm{ng} / \mathrm{ml})$ or with the extrapolated value where possible. Data are given as mean $\pm \mathrm{SD}(n=5)$ 

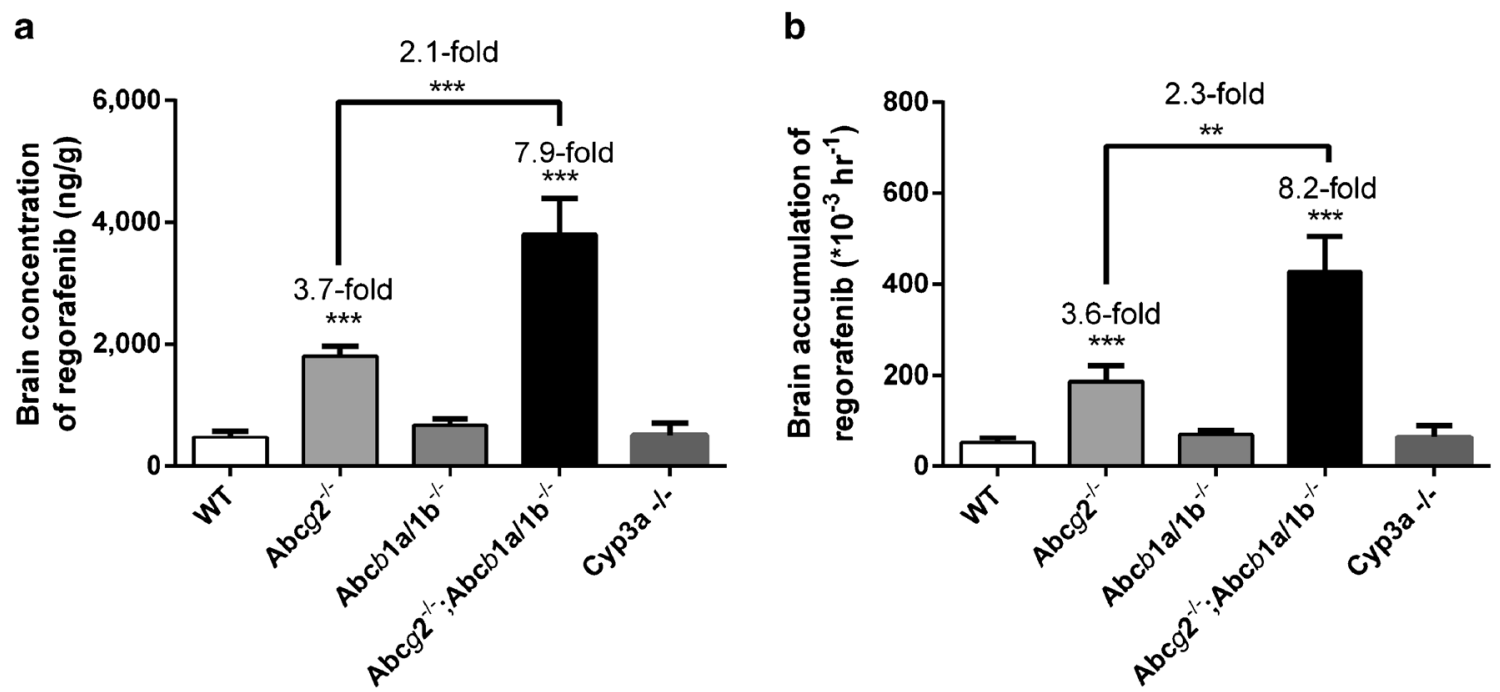

C

d
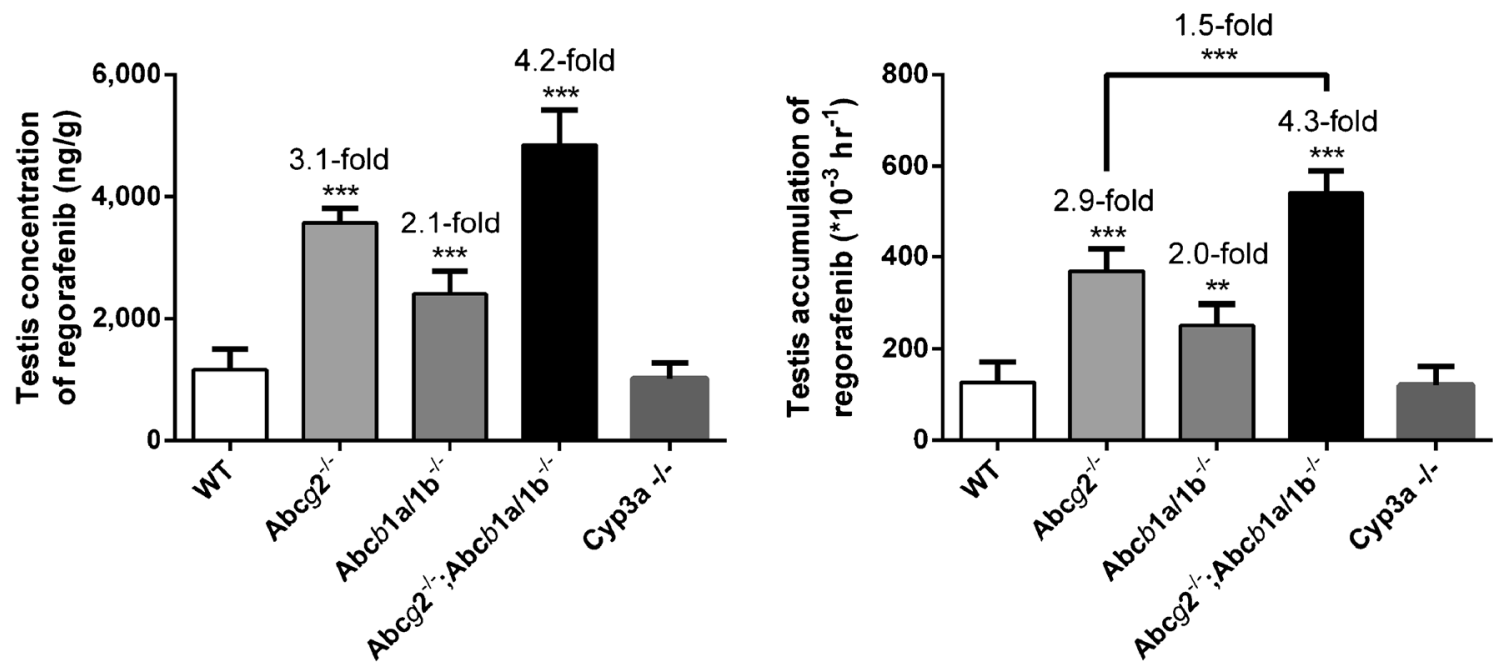

Fig. 6 Brain concentration (a), relative brain accumulation (b), testis concentration (c) and testis accumulation (d) of regorafenib in male WT, Abcg2 ${ }^{-1-}$, Abcb/ a/

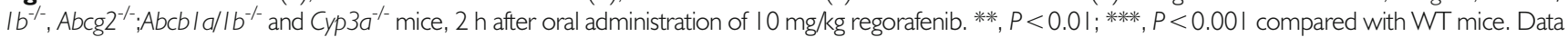
are presented as mean $\pm \mathrm{SD}(n=5)$. Where necessary, data were log-transformed to normalize the SDs between study groups.

not enough to result in reliably detectable levels of M2 and M5. Also in patients substantial levels of M2 and M5 are detectable after subsequent daily oral administrations of regorafenib $(17,41)$.

In spite of several performed clinical trials, none have yet systematically assessed the efficacy of regorafenib in central nervous system (CNS) metastases. We think that our findings can be a good source for future clinical studies of cancer patients with CNS involvement, as we here showed a clear impact of ABCB1 and $\mathrm{ABCG} 2$ in restricting brain penetration of regorafenib. Moreover, based on our previous experience $(14,20,28)$, we suggest that combined administration of regorafenib with $\mathrm{ABCB} 1$ and $\mathrm{ABCG} 2$ inhibitors such as elacridar might improve the brain concentration and thus efficacy of regorafenib against metastases located behind an intact BBB.

\section{CONCLUSION}

We conclude that the multikinase inhibitor regorafenib is transported well by hABCG2 and mAbcg2, and modestly by $\mathrm{hABCB} 1$ in vitro. This is supported in vivo in mice where brain and testis accumulation are restricted mostly by Abcg2 and additionally by Abcbl. These results indicate that coadministration of ABCG2 and/or ABCB1 inhibitors may increase exposure of regorafenib and its active M2 metabolite in patients, thus providing an option to 
better treat (micro)metastases behind a functionally intact blood-brain barrier.

\section{ACKNOWLEDGMENTS AND DISCLOSURES}

The research group of A.H. Schinkel receives revenue from commercial distribution of some of the mouse strains used in this study.

Anita Kort and Selvi Durmus contributed equally.

\section{REFERENCES}

1. Schinkel AH, Wagenaar E, Mol CA, van Deemter L. P-glycoprotein in the blood-brain barrier of mice influences the brain penetration and pharmacological activity of many drugs. J Clin Invest. 1996;97(11):2517-24.

2. Chen Y, Agarwal S, Shaik NM, Chen C, Yang Z, Elmquist WF. Pglycoprotein and breast cancer resistance protein influence brain distribution of dasatinib. J Pharmacol Exp Ther. 2009;330(3):956-63.

3. Noguchi K, Katayama K, Sugimoto Y. Human ABC transporter ABCG2/BCRP expression in chemoresistance: basic and clinical perspectives for molecular cancer therapeutics. Pharmgenomics Pers Med. 2014;7:53-64.

4. Wilhelm SM, Dumas J, Adnane L, Lynch M, Carter CA, Schutz G, et al. Regorafenib (BAY 73-4506): a new oral multikinase inhibitor of angiogenic, stromal and oncogenic receptor tyrosine kinases with potent preclinical antitumor activity. Int J Cancer. 2011;129(1):245-55.

5. Grothey A, Van Cutsem E, Sobrero A, Siena S, Falcone A, Ychou $\mathrm{M}$, et al. Regorafenib monotherapy for previously treated metastatic colorectal cancer (CORRECT): an international, multicentre, randomised, placebo-controlled, phase 3 trial. Lancet. 2013;381(9863):303-12.

6. Center for Drug Evaluation and Research of the US Department of Health and Human Services, Food and Drug Administration. Clinical pharmacology and biopharmaceutics review(s). 2014 June 5. Available from: http://www.accessdata.fda.gov/drugsatfda_docs/ nda/2012/203085Orig1s000ClinPharmR.pdf.

7. European Medicines Agency. Stivarga summary of product characteristics. 2014 September 24. Available from: http://www.ema. europa.eu/docs/en_GB/document_library/EPAR_-_Product_ Information/human/002573/WC500149164.pdf.

8. Demetri GD, Reichardt P, Kang YK, Blay JY, Rutkowski P, Gelderblom $\mathrm{H}$, et al. Efficacy and safety of regorafenib for advanced gastrointestinal stromal tumours after failure of imatinib and sunitinib (GRID): an international, multicentre, randomised, placebocontrolled, phase 3 trial. Lancet. 2013;381(9863):295-302.

9. Sallinen H, Anttila M, Grohn O, Koponen J, Hamalainen K, Kholova I, et al. Cotargeting of VEGFR-1 and -3 and angiopoietin receptor Tie2 reduces the growth of solid human ovarian cancer in mice. Cancer Gene Ther. 2011;18(2):100-9.

10. Tsai JH, Lee WM. Tie2 in tumor endothelial signaling and survival: implications for antiangiogenic therapy. Mol Cancer Res. 2009;7(3): 300-10.

11. Bruix J, Tak WY, Gasbarrini A, Santoro A, Colombo M, Lim HY, et al. Regorafenib as second-line therapy for intermediate or advanced hepatocellular carcinoma: multicentre, open-label, phase II safety study. Eur J Cancer. 2013;49(16):3412-9.

12. Poller B, Iusuf D, Sparidans RW, Wagenaar E, Beijnen JH, Schinkel AH. Differential impact of P-glycoprotein (ABCB1) and breast cancer resistance protein (ABCG2) on axitinib brain accumulation and oral plasma pharmacokinetics. Drug Metab Dispos. 2011;39(5):729-35.
13. Agarwal S, Sane R, Ohlfest JR, Elmquist WF. The role of the breast cancer resistance protein $(\mathrm{ABCG} 2)$ in the distribution of sorafenib to the brain. J Pharmacol Exp Ther. 201 1;336(1):223-33.

14. Lagas JS, van Waterschoot RA, Sparidans RW, Wagenaar E, Beijnen JH, Schinkel AH. Breast cancer resistance protein and Pglycoprotein limit sorafenib brain accumulation. Mol Cancer Ther. 2010;9(2):319-26.

15. Hu S, Chen Z, Franke R, Orwick S, Zhao M, Rudek MA, et al. Interaction of the multikinase inhibitors sorafenib and sunitinib with solute carriers and ATP-binding cassette transporters. Clin Cancer Res. 2009;15(19):6062-9.

16. Zopf D, Heinig R, Thierauch KH, Hirth-Dietrich C, Hafner F, Christensen O, Lin T, Wilhelm S, Radtke M. Regorafenib (BAY 73-4506): preclinical pharmacology and clinical identification and quantification of its major metabolites [abstract]. In: Proceedings of the 101st Annual Meeting of the American Association for Cancer Research. Washington DC, Philadelphia (PA): Cancer Res; 2010 Apr 17-21. p. Suppl.

17. Mross K, Frost A, Steinbild S, Hedbom S, Buchert M, Fasol $\mathrm{U}$, et al. A phase I dose-escalation study of regorafenib (BAY 73-4506), an inhibitor of oncogenic, angiogenic, and stromal kinases, in patients with advanced solid tumors. Clin Cancer Res. 2012;18(9):2658-67.

18. Luethi D, Durmus S, Schinkel AH, Schellens JH, Beijnen JH, Sparidans RW. Liquid chromatography-tandem mass spectrometric assay for the multikinase inhibitor regorafenib in plasma. Biomed Chromatogr. 2014.

19. Evers R, Kool M, van Deemter L, Janssen H, Calafat J, Oomen LC, et al. Drug export activity of the human canalicular multispecific organic anion transporter in polarized kidney MDCK cells expressing cMOAT (MRP2) cDNA. J Glin Invest. 1998;101(7):1310-9.

20. Durmus S, Sparidans RW, Wagenaar E, Beijnen JH, Schinkel AH. Oral availability and brain penetration of the B-RAFV600E inhibitor vemurafenib can be enhanced by the P-glycoprotein (ABCB1) and breast cancer resistance protein (ABCG2) inhibitor elacridar. Mol Pharm. 2012;9(11):3236-45.

21. Schinkel AH, Mayer U, Wagenaar E, Mol CA, van Deemter L, Smit JJ, et al. Normal viability and altered pharmacokinetics in mice lacking mdrl-type (drug-transporting) P-glycoproteins. Proc Natl Acad Sci U S A. 1997;94(8):4028-33.

22. Jonker JW, Buitelaar M, Wagenaar E, Van Der Valk MA, Scheffer GL, Scheper RJ, et al. The breast cancer resistance protein protects against a major chlorophyll-derived dietary phototoxin and protoporphyria. Proc Natl Acad Sci U S A. 2002;99(24):15649-54.

23. Jonker JW, Merino G, Musters S, van Herwaarden AE, Bolscher E, Wagenaar E, et al. The breast cancer resistance protein BCRP (ABCG2) concentrates drugs and carcinogenic xenotoxins into milk. Nat Med. 2005; 1 1(2):127-9.

24. van Waterschoot RA, Lagas JS, Wagenaar E, van der Kruijssen CM, van Herwaarden AE, Song JY, et al. Absence of both cytochrome P450 3A and P-glycoprotein dramatically increases docetaxel oral bioavailability and risk of intestinal toxicity. Cancer Res. 2009;69(23): 8996-9002.

25. Dai H, Marbach $P$, Lemaire M, Hayes M, Elmquist WF. Distribution of STI-571 to the brain is limited by Pglycoprotein-mediated efflux. J Pharmacol Exp Ther. 2003;304(3): 1085-92.

26. Pharmaceuticals and Medical Devices Agency Japan. Review report on Stivarga. 2014 June 5. Available from: http://www.pmda.go.jp/ english/service/pdf/drugs/stivarga mar2010 e.pdf.

27. Tang SC, de Vries N, Sparidans RW, Wagenaar E, Beijnen $\mathrm{JH}$, Schinkel AH. Impact of P-glycoprotein (ABCB 1) and breast cancer resistance protein (ABCG2) gene dosage on plasma pharmacokinetics and brain accumulation of dasatinib, sorafenib, and sunitinib. J Pharmacol Exp Ther. 2013;346(3): 486-94. 
28. Tang SC, Lankheet NA, Poller B, Wagenaar E, Beijnen JH, Schinkel $\mathrm{AH}$. P-glycoprotein $(\mathrm{ABCB} 1)$ and breast cancer resistance protein (ABCG2) restrict brain accumulation of the active sunitinib metabolite N-desethyl sunitinib. J Pharmacol Exp Ther. 2012;341(1):164-73.

29. Uchida Y, Ohtsuki S, Katsukura Y, Ikeda C, Suzuki T, Kamiie J, et al. Quantitative targeted absolute proteomics of human bloodbrain barrier transporters and receptors. J Neurochem. 201 1;117(2): 333-45.

30. Kalvass JC, Pollack GM. Kinetic considerations for the quantitative assessment of efflux activity and inhibition: implications for understanding and predicting the effects of efflux inhibition. Pharm Res. 2007;24(2):265-76.

31. Zamek-Gliszczynski MJ, Kalvass JC, Pollack GM, Brouwer KL. Relationship between drug/metabolite exposure and impairment of excretory transport function. Drug Metab Dispos. 2009;37(2):386-90.

32. Kodaira H, Kusuhara H, Ushiki J, Fuse E, Sugiyama Y. Kinetic analysis of the cooperation of P-glycoprotein (P-gp/Abcbl) and breast cancer resistance protein (Bcrp/Abcg2) in limiting the brain and testis penetration of erlotinib, flavopiridol, and mitoxantrone. J Pharmacol Exp Ther. 2010;333(3):788-96.

33. Durmus S, Xu N, Sparidans RW, Wagenaar E, Beijnen JH, Schinkel AH. P-glycoprotein (MDR1/ABCB1) and breast cancer resistance protein (BCRP/ABCG2) restrict brain accumulation of the JAK1/2 inhibitor, CYT387. Pharmacol Res. 2013;76:9-16.

34. Wang T, Agarwal S, Elmquist WF. Brain distribution of cediranib is limited by active efflux at the blood-brain barrier. J Pharmacol Exp Ther. 2012;341(2):386-95.

35. Chuan Tang S, Nguyen LN, Sparidans RW, Wagenaar E, Beijnen $\mathrm{JH}$, Schinkel AH. Increased oral availability and brain accumulation of the ALK inhibitor crizotinib by coadministration of the Pglycoprotein $(\mathrm{ABCB} 1)$ and breast cancer resistance protein (ABCG2) inhibitor elacridar. Int J Cancer. 2014;134(6):1484-94.
36. Tang SC, Sparidans RW, Cheung KL, Fukami T, Durmus S, Wagenaar E, et al. P-glycoprotein, CYP3A, and plasma carboxylesterase determine brain and blood disposition of the mTOR Inhibitor everolimus (Afinitor) in mice. Clin Cancer Res. 2014;20(12):3133-45.

37. Vaidhyanathan S, Mittapalli RK, Sarkaria JN, Elmquist WF. Factors influencing the CNS distribution of a novel MEK-1/2 inhibitor: implications for combination therapy for melanoma brain metastases. Drug Metab Dispos. 2014;42(8):1292-300.

38. Lin F, de Gooijer MC, Roig EM, Buil LC, Christner SM, Beumer $\mathrm{JH}$, et al. ABCB1, ABCG2, and PTEN determine the response of glioblastoma to temozolomide and ABT-888 therapy. Clin Cancer Res. 2014;20(10):2703-13.

39. Agarwal S, Hartz AM, Elmquist WF, Bauer B. Breast cancer resistance protein and P-glycoprotein in brain cancer: two gatekeepers team up. Curr Pharm Des. 201 1;17(26):2793-802.

40. Kamiie J, Ohtsuki S, Iwase R, Ohmine K, Katsukura Y, Yanai K, et al. Quantitative atlas of membrane transporter proteins: development and application of a highly sensitive simultaneous LC/MS/MS method combined with novel in-silico peptide selection criteria. Pharm Res. 2008;25(6):1469-83.

41. Strumberg D, Clark JW, Awada A, Moore MJ, Richly H, Hendlisz A, et al. Safety, pharmacokinetics, and preliminary antitumor activity of sorafenib: a review of four phase I trials in patients with advanced refractory solid tumors. Oncologist. 2007;12(4):426-37.

42. Dankers AC, Sweep FC, Pertijs JC, Verweij V, van den Heuvel JJ, Koenderink JB, et al. Localization of breast cancer resistance protein (Bcrp) in endocrine organs and inhibition of its transport activity by steroid hormones. Cell Tissue Res. 2012;349(2):551-63.

43. Holash JA, Harik SI, Perry G, Stewart PA. Barrier properties of testis microvessels. Proc Natl Acad Sci U S A. 1993;90(23):1 1069-73. 